\title{
Two-Step Synthesis of CuS/C@PANI Nanocomposite as Advanced Electrode Materials for Supercapacitor Applications
}

\author{
Qing Liu ${ }^{1}$, Shihang Zhang ${ }^{1,2, *}$ and Yan $\mathrm{Xu}{ }^{1,2}$ \\ 1 Department of Electric Engineering, North China Electric Power University, Baoding 071003, China; \\ 51351103@ncepu.edu.cn (Q.L.); xuyanhd@ncepu.edu.cn (Y.X.) \\ 2 State Key Laboratory of New Energy and Electric Power Systems, North China Electric Power University, \\ Baoding 071003, China \\ * Correspondence: zsh1130@ncepu.edu.cn; Tel.: +86-157-3322-9737
}

Received: 27 April 2020; Accepted: 26 May 2020; Published: 28 May 2020

\begin{abstract}
In this study, the dense cloud-like structured CuS nanoparticles were successfully prepared using a simple two-step hydrothermal method. The experimental temperature was the most important factor that affected the microstructure and surface functions of $\mathrm{CuS} / \mathrm{C}$. Therefore, the $\mathrm{CuS} / \mathrm{C}$ electrodes were synthesized at different temperatures $\left(80^{\circ} \mathrm{C}, 120^{\circ} \mathrm{C}\right.$, and $\left.160{ }^{\circ} \mathrm{C}\right)$. Subsequently, their crystallographic phase and morphologies as well as the structure of the as-prepared electrodes were analyzed in detail. The electrode prepared at $120{ }^{\circ} \mathrm{C}(\mathrm{CuS} / \mathrm{C}-120)$ was determined to have a perfect microstructure, high specific capacitance, and good rate performance. To further improve the electrochemical performance of this electrode, it was combined with polyaniline (PANI) to obtain a CuS/C-120@PANI electrode via the cyclic voltammetric electrodeposition method. The CuS/C-120@PANI electrode exhibits a specific capacitance of $425.53 \mathrm{Fg}^{-1}$ at a current density of $1 \mathrm{Ag}^{-1}$ and a good cycling stability of $89.86 \%$ after 3000 cycles. The perfect architecture of CuS/C-120@PANI maximizes the synergistic effect between its different components and provides abundant electrochemically reactive sites, promoting the diffusion and transfer of electrolyte ions during the electrochemical reaction processes. Detailed analysis shows that the CuS/C-120@PANI electrode has great potential for use in high-performance energy storage devices.
\end{abstract}

Keywords: CuS/C-120@PANI; nanocomposites; supercapacitor; electrode material

\section{Introduction}

Owing to the heavy consumption of fossil fuels and the increasing environmental pollution, renewable energy power generation technologies, such as wind, solar, and tidal energy have rapidly developed. Further, new energy conversion and storage devices are urgently required. Supercapacitors (SCs) exhibit considerable potential for use in electrical equipment and other applications because they can quickly store energy and effectively provide electrical energy [1-3]. When compared with batteries, SCs have the advantages of a large energy density, long cycle life, and fast charge-discharge rates $[4,5]$. According to the charge storage mechanism, the energy storage of SCs can be divided into two types based on the ion adsorption at the electrode-electrolyte interface or the reversible redox reaction on the electrode surface. Carbon materials are generally used as electrode materials in double-layer capacitors owing to their good cycle stability. However, they have a low energy density [6]. Transition metal oxides and conductive polymers are used in pseudocapacitors owing to their high specific capacitances $[7,8]$. SCs experience a decrease in cycle life owing to the occurrence of the Faraday redox reaction [9]. Therefore, the development of new high-quality and environment-friendly electrode materials for SCs is the key to optimize their excellent performance [10]. 
Recently, electrode materials, such as cobalt sulfide [11] and molybdenum sulfide [12], have been widely used in SCs owing to the unique physical and chemical properties exhibited by transition metal sulfides and oxides in the field of energy storage. CuS is an important semiconductor material that is easy to synthesize. Further, it can be prepared from extensively used abundant raw materials, making it an ideal electrode material. Li et al. synthesized a streamlined CuS nanoarray with respect to graphene nanosheets [13]. Liang et al. prepared CuS via a facile hydrolysis method with a graphene multilayered two-dimensional (2D) structure [14]. Huang et al. synthesized a CuS/multi-walled carbon nanotube (MWCNT) composite electrode material with a hierarchical structure via a step hydrothermal method [15]. However, it has a relatively low conductivity when compared with carbon materials. Therefore, it is highly desirable to study the CuS composites with an electronically conductive substance.

Based on the previous research results, $\mathrm{CuS} / \mathrm{C}$ electrodes were synthesized in this study via a two-step hydrothermal method to improve its conductivity. The metal-organic framework (MOF) materials exhibit the advantages of good thermal stability, large specific surface area, and adjustable pore size [16-18]. MOFs have unique structures and contain suitable channels that allow the passage of electrolytes. Further, a conductive material that can transport charges can be added into the framework, making MOFs suitable templates to prepare CuS/C electrode materials. Therefore, an MOF template can be used to effectively prepare CuS/C electrode materials. The performance of any SC electrode material is dependent on many parameters, including the experimental temperature, reaction time, and actual duty cycle $[19,20]$. Thus, the electrochemical performance is affected by the synthesis and properties of the nanostructured electrode material. Hence, this study focuses on the experimental temperature. Furthermore, the conductivity of electrode materials can be improved by conducting polymers. Polyaniline (PANI) is a promising conducting polymer in the energy storage field because of its abundance, high specific capacitance, and high electron conductivity $\left(30-200 \mathrm{~S} \mathrm{~cm}^{-1}\right)$ compared with those of other polymers [21,22]. Further, PANI can achieve oxidation-reduction reactions in various states using electrochemical methods. PANI exhibits good dispersibility and structural integrity when compared to polyacetylene; therefore, it is considered to be a highly promising material for energy-storage applications [23]. Recently, the synthesis and supercapacitor properties of PANI composites have been studied. Zhu et al. [24] constructed a hierarchical ZnO@MOF@PANI on carbon cloth for supercapacitor electrodes. The specific capacitance of ZnO@MOF@PANI is as high as $340.7 \mathrm{Fg}^{-1}$ at a current density of $1 \mathrm{Ag}^{-1}$. Jafari et al. [25] synthesized MOF-199 and the composite HKUST-1/PANI. The specific capacitance of HP can approach to be $270 \mathrm{Fg}^{-1}$ at $1 \mathrm{Ag}^{-1}$. Wang et al. had reported the PANI-ZIF-67-CC electrode with a high specific capacitance of $2146 \mathrm{mF} / \mathrm{cm}^{2}$ at $10 \mathrm{mVs}^{-1}$ [26]. The composites containing several kinds of materials can show the advantages of different electrode materials. Furthermore, the positive synergy of each electrode material can improve the electrochemical performance. Based on the above discussion, the highly conductive CuS/C@PANI nanocomposite electrode material is expected to be an excellent electrode in energy storage devices. To the best of our knowledge, the composite materials comprising PANI and copper sulfide for supercapacitors have been rarely reported.

In this study, CuS/C electrodes were synthesized at different temperatures $\left(80^{\circ} \mathrm{C}, 120^{\circ} \mathrm{C}\right.$, and $160^{\circ} \mathrm{C}$ ), and their morphologies were compared; furthermore, their electrochemical performances were investigated in a $3 \mathrm{M} \mathrm{KCl}$ neutral electrolyte. A CuS/C-120@PANI nanocomposite that exhibits a high specific capacitance and the best cycling stability was subsequently prepared at a curing temperature of $120^{\circ} \mathrm{C}$. When compared with other studies, the CuS/C-120@PANI synthesized in this study exhibited two advantages. First, it has a unified and highly ordered special framework owing to the use of a $\mathrm{Cu}-\mathrm{MOF}$ as the precursor. Second, it exhibits good cycling stability and high rate capability owing to the addition of the conductive polymer PANI. 


\section{Materials and Methods}

\subsection{Materials}

All the chemicals were used as received. Copper nitrate trihydrate $\left(\mathrm{Cu}\left(\mathrm{NO}_{3}\right)_{2} \cdot 3 \mathrm{H}_{2} \mathrm{O}, 99.99 \%\right)$ was supplied by Tianjin Tianli Chemical Co., Ltd. (Tianjin, China), 1,3,5-benzenetricarboxylic acid ( $\left.\mathrm{H}_{3} \mathrm{BTC}, 95 \%\right)$, polyvinyl pyrrolidone (PVP, 99\%), thioacetamide $\left(\mathrm{CH}_{3} \mathrm{CSNH}_{2}, 99 \%\right)$, aniline (PANI, 99.5\%), potassium chloride ( $\mathrm{KCl}, 99.5 \%)$, and 1-methyl-2-pyrrolidinone (NMP, 99\%) were acquired from Aladdin, and solvents (N, N-dimethylformamide and ethanol with $99.98 \%$ and $99 \%$ of purity, respectively) were obtained from Aladdin Company (Shanghai, China). All the chemicals were of the analytical-reagent grade and used as received without any further purification. The solutions were prepared using ultrapure water $(18.2 \mathrm{M} \Omega \cdot \mathrm{cm})$ throughout the experiments. Hydrophobic carbon cloth (CC, $1 \mathrm{~cm} \times 2 \mathrm{~cm}$, WOS1002) was provided by CeTech Co. Ltd., Taiwan, China.

\subsection{Synthesis of the CuS/C-80/120/160 Materials}

To prepare the CuS/C-based electrode materials used in this study, the first step was to prepare a $\mathrm{Cu}-\mathrm{MOF}$ precursor [27]. $\mathrm{Cu}\left(\mathrm{NO}_{3}\right)_{2} \cdot 3 \mathrm{H}_{2} \mathrm{O}(0.7248 \mathrm{~g})$ and $\mathrm{H}_{3} \mathrm{BTC}(0.4242 \mathrm{~g})$ were dissolved in $12 \mathrm{~mL}$ of 9:3 $(v / v)$ dimethylformamide:ethanol (DMF:EtOH) under ultrasonication and magnetic stirring for $40 \mathrm{~min}$, respectively. Then, the BTC solution was added dropwise to the $\mathrm{Cu}^{2+}$ solution under rapid stirring. Once the two solutions were mixed, $0.1 \mathrm{~g}$ of polyvinyl pyrrolidone (PVP) was added dropwise to the solution as a surface stabilizer. Subsequently, the reaction mixture was sealed in a $100 \mathrm{~mL}$ Teflon-lined stainless steel autoclave and heated in a water bath at $140{ }^{\circ} \mathrm{C}$ for $24 \mathrm{~h}$. After the completion of the reaction, the sample was allowed to naturally cool to room temperature and subsequently washed thrice using EtOH. Finally, the resulting solid powder was annealed under argon atmosphere at $350{ }^{\circ} \mathrm{C}$ for $12 \mathrm{~h}$ to obtain a black powder.

The next stage was to prepare the CuS/C electrode materials. Three sets of the synthesized $\mathrm{Cu}-\mathrm{MOF}(0.0800 \mathrm{~g})$ and thioacetamide $(0.1800 \mathrm{~g})$ of equal mass were weighed and dissolved in 20 $\mathrm{mL}$ of ethylene glycol. The particles were subsequently dispersed using an ultrasonic oscillator to obtain homogeneous aqueous solutions. Furthermore, the two solutions were mixed together and evenly stirred, resulting in the immediate appearance of a bluish-green precipitate. After the mixtures were stirred for $30 \mathrm{~min}$, they were transferred to Teflon-lined stainless steel autoclaves and placed in three identical vacuum drying ovens set to a temperature gradient to heat for $12 \mathrm{~h}$. The experimental temperatures were $80{ }^{\circ} \mathrm{C}, 120{ }^{\circ} \mathrm{C}$, and $160{ }^{\circ} \mathrm{C}$. After the vulcanization reaction, the samples were allowed to cool to room temperature, and they were subsequently washed thrice using EtOH. Finally, the resulting black products indicated the formation of $\mathrm{CuS} / \mathrm{C}$. The samples were labeled as $\mathrm{CuS} / \mathrm{C}-80$, $\mathrm{CuS} / \mathrm{C}-120$, and CuS/C-160 based on the vulcanization temperature considered in each case. During the experiments, all the parameters, except the experimental temperature, were maintained unchanged. Therefore, the experimental temperature can be considered for comparison purposes.

\subsection{Fabrication of the CuS/C-120@PANI Electrode Electrodes}

PANI was deposited on the newly prepared CuS/C-120 electrode in the freshly prepared $3 \mathrm{M} \mathrm{KCL}$ solution containing 0.1 M PANI via a cyclic voltammetric electrodeposition [28], which was performed in a three-electrode system from -0.3 to $0.6 \mathrm{~V}$ at $10 \mathrm{mV}^{-1}$ for 20 cycles. Here, the $\mathrm{Ag} / \mathrm{AgCl}$ and $\mathrm{Pt}$ foil were applied as the reference electrode and counter electrode. When the deposition was completed, the electrode was gently rinsed using distilled water and dried prior to use. The specific experimental process is presented in Figure 1. 


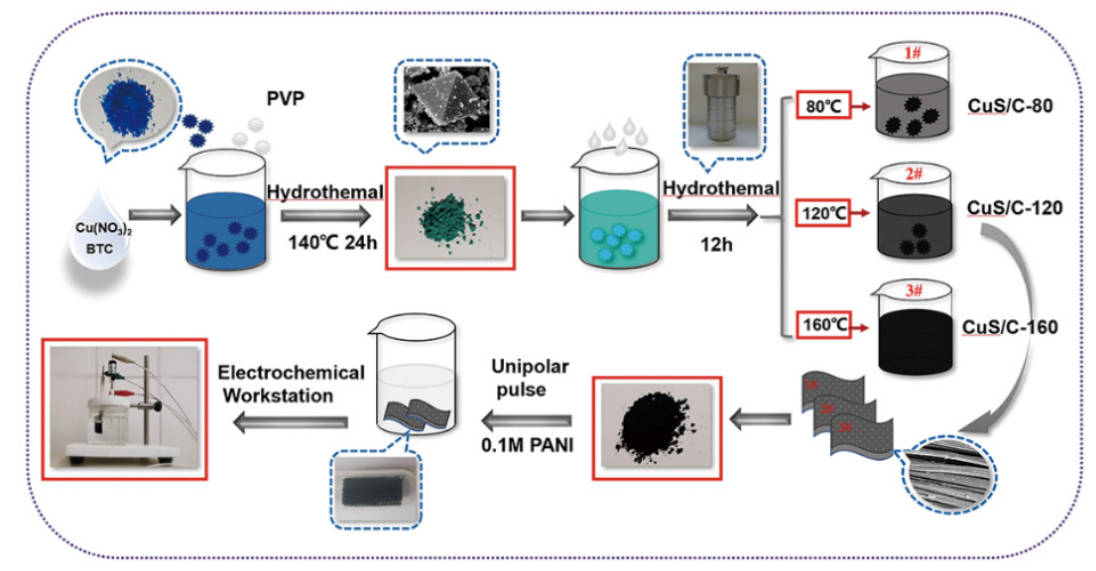

Figure 1. Schematic illustration of the fabrication of CuS/C-120@PANI nanocomposite.

\subsection{Morphological and Structural Characterization}

The crystal structure of the samples was identified through X-ray diffraction (XRD) measurements recorded on an X-ray diffractometer (Bruker D8, Rigaku, Tokyo, Japan, Cu K $\alpha$ radiation, $\lambda=0.15406 \mathrm{~nm}$ ). The microstructure of the samples was observed with FESEM (HITACHI, S4800, Tokyo, Japan) and TEM (JEOL, 2100F, Tokyo, Japan). Fourier transform infrared spectroscopy spectra were conducted by an FTIR spectrometer (Thermo Nicolet 5700 system, Hitachi, Berlin, Germany). XPS (Thermo ESCALAB 250Xi, Shanghai, China) was performed to identify surface com-position of ternary composite inside an ultrahigh vacuum system with an excited MtgK $\alpha$ source (1486.6 eV). Raman spectrum was obtained using a $514 \mathrm{~nm}$ excitation laser with a WITec Raman instrument (Renishaw PLC, London, United Kingdom). In addition, the specific surface area of as-fabricated samples was evaluated by utilizing Brunauer-Emmett-Teller analysis (TriStar 3020, Micromeritics, New York, NY, USA).

\subsection{Electrochemical Analysis}

The working electrodes were prepared by mixing $80 \%$ active materials, $15 \%$ polyvinylidene fluoride, and 5\% acetylene black. Then, NMP was added dropwise and stirred to prepare slurry. The resulting slurry was coated onto the CC, which was followed by drying at $60^{\circ} \mathrm{C}$ for $12 \mathrm{~h}$ in a vacuum oven.

The electrochemical performance of all electrodes was performed with the electrochemical workstation (CHI 660E, Chenhua, China) in a typical three-electrode system with $3 \mathrm{M} \mathrm{KCL}$ aqueous solution as the electrolyte. $\mathrm{Pt}, \mathrm{Ag} / \mathrm{AgCl}$, and $\mathrm{CuS} / \mathrm{C}$ electrodes were operated as the counter, reference, and working electrodes, respectively. All the electrochemical test including cyclic voltammetry $(\mathrm{CV})$ and galvanostatic charge-discharge (GCD) were carried out from -0.3 to $0.6 \mathrm{~V}$. The electrochemical impedance spectroscopy (EIS) test was observed within a frequency range from $10^{-2}$ to $10^{5} \mathrm{~Hz}$ with an amplitude of $5 \mathrm{mV}$. The cycling activity was evaluated by a continuous cyclic voltammetry process at a scan rate $10 \mathrm{mV}^{-1}$ for over 3000 cycles. The specific capacitance was calculated from the CV cures and GCD curves according to the following equation [29]:

$$
\begin{gathered}
C=\frac{\int I \cdot \mathrm{d} V}{2 v \cdot m \cdot \Delta V} \\
C=\frac{I \cdot \Delta t}{m \cdot \Delta V}
\end{gathered}
$$

where $I(\mathrm{~A})$ is the charge-discharge current, $m(\mathrm{~g})$ is the weight of active materials on electrode, $t(\mathrm{~s})$ is the discharge time, $V(\mathrm{~V})$ is the potential window, and $v\left(\mathrm{mV}^{-1}\right)$ is the scan rate. 


\section{Results Discussion}

\subsection{Morphological and Structural Characterization}

The structures of CuS/C-80, CuS/C-120, and CuS/C-160 were investigated based on the powder X-ray diffraction (PXRD) measurements. The PXRD patterns of the CuS/C samples at different experimental temperatures are presented in Figure 2, where the diffraction peaks of the three patterns at $2 \theta=27.223^{\circ}, 27.738^{\circ}, 29.323^{\circ}, 31.914^{\circ}, 38.915^{\circ}, 48.016^{\circ}, 52.777^{\circ}$, and $59.428^{\circ}$ can be assigned to the (100), (101), (102), (103), (105), (110), (108), and (116) planes of CuS (PDF NO.06-0464), respectively. No diffraction peaks could be observed from other substances, indicating that the synthesized CuS samples do not contain impurities. When compared with CuS/C-80 and CuS/C-160, the PXRD pattern of CuS/C-120 shows the sharpest peaks, implying that carbon in the composites obtained at $120{ }^{\circ} \mathrm{C}$ had a higher degree of crystallization. Additionally, the CuS crystallite size were calculated via a Scherrer equation [30]:

$$
D=\frac{K \lambda}{\beta \cos \theta}
$$

where " $K$ " is the shape factor having constant value 0.9, " $\lambda$ " is X-rays wavelength $(1.541874 \AA$ ), " $\beta$ " is the full width at half maximum (FWHM) of the high-intensity peak and $\theta$ is the Bragg's angle of the radians. The average crystallite size of the $\mathrm{CuS}$ were $8.1 \mathrm{~nm}, 9.7 \mathrm{~nm}$, and $8.4 \mathrm{~nm}$ for CuS/C-80, CuS/C-120, and CuS/C-160, respectively. Therefore, CuS/C-120 has the largest crystallite size and the highest degree of crystallization, as shown in Table 1. CuS/C exhibits strong diffraction peaks at low angles, indicating the presence of abundant of pores in the sample. Therefore, the crystallization of the composites changes upon an increase in the hydrothermal temperature, which may affect their electrochemical performance.

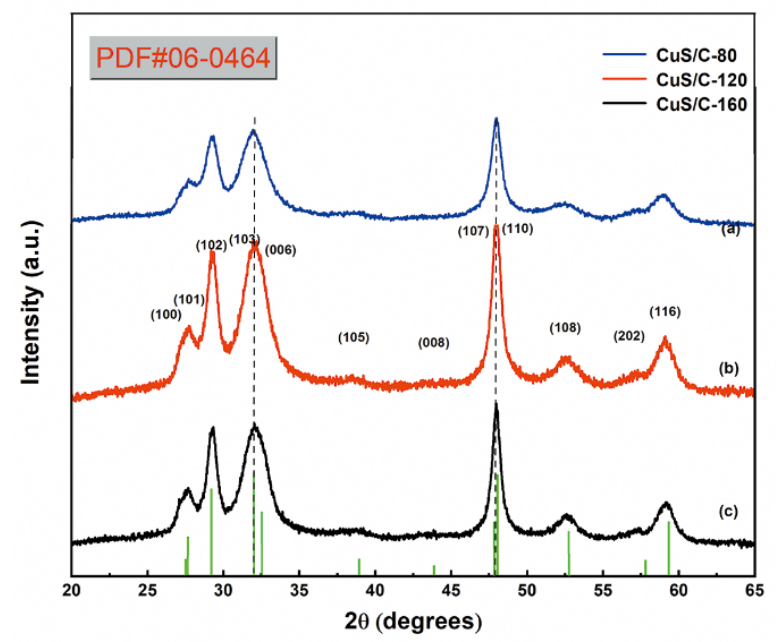

Figure 2. Powder X-ray diffraction (PXRD) patterns of (a) CuS/C-80, (b) CuS/C-120, and (c) CuS/C-160 nanoparticles.

Table 1. XRD analyses of the CuS/C-120 material (CuS-peaks). FWHM: full width at half maximum.

\begin{tabular}{cccccccc}
\hline No. & $\mathbf{2 \theta ^ { \circ }}$ & FWHM & Area $\left(\mathbf{c t s} \times \mathbf{2}^{\circ}\right)$ & d-Spacing $(\mathbf{\AA})$ & Height (cts) & Rel. Int. (\%) & HKL \\
\hline 1 & 27.738 & 2.473 & 75,853 & 3.2204 & 578 & 37.2 & 101 \\
2 & 29.323 & 0.842 & 50,740 & 3.0524 & 1134 & 24.9 & 102 \\
3 & 31.914 & 1.948 & 203,710 & 2.8050 & 1670 & 100 & 103 \\
4 & 38.915 & 2.550 & 15,645 & 2.3132 & 15,645 & 7.7 & 105 \\
5 & 48.016 & 0.774 & 113,625 & 1.8963 & 2049 & 55.8 & 110 \\
6 & 52.777 & 2.352 & 34,255 & 1.7383 & 249 & 16.8 & 108 \\
7 & 59.428 & 1.947 & 73,385 & 1.5635 & 564 & 36.0 & 116 \\
\hline
\end{tabular}


The graphitized structures of the CuS/C samples at different temperatures were further analyzed using Raman spectroscopy, the results of which are shown in Figure 3. In the Raman spectra, two intense peaks can be observed at 1342.5, $1585 \mathrm{~cm}^{-1}$ and $1585 \mathrm{~cm}^{-1}$, which can be assigned as the D and G bands, respectively. The presence of the $\mathrm{D}$ band peak can be attributed to the disordered structure of the prepared carbon electrode material, whereas the $G$ band peak represents the vibration of the $\mathrm{sp}^{2}$ hybridized carbon atoms. The $\mathrm{I}_{\mathrm{D}}$ to $\mathrm{I}_{\mathrm{G}}$ ratio indicates the degree of graphitization in the structure. The measured values of $\mathrm{I}_{\mathrm{D}} / \mathrm{I}_{\mathrm{G}}$ were $0.90,0.86$, and 0.88 for CuS/C-80, CuS/C-120, and CuS/C-160, respectively. The smaller the ratio, the higher will be the degree of graphitization and the more disordered will be the structure. The $\mathrm{I}_{\mathrm{D}} / \mathrm{I}_{\mathrm{G}}$ of $\mathrm{CuS} / \mathrm{C}-120$ is lower compared to CuS/C-80 and CuS/C-160, expressing that the graphitic crystalline structure of CuS/C-120 is superior to that of CuS/C-80 and $\mathrm{CuS} / \mathrm{C}-160$. In another word, it indicates that the CuS/C-80 and CuS/C-160 possess higher disordered graphitic structure than CuS/C-120. At the same time, the increase in the intensity of the D-band of $\mathrm{CuS} / \mathrm{C}-80$ and $\mathrm{CuS} / \mathrm{C}-160$ revealed the presence of additional crystal defects and structural disorderness. However, the CuS/C-120 exhibits the lower $\mathrm{I}_{\mathrm{D}} / \mathrm{I}_{\mathrm{G}}$ specific value than that of $\mathrm{CuS} / \mathrm{C}-80$ and CuS/C-160, which is due to the reduction of disordered graphitic structure of the surface when the temperature is $120^{\circ} \mathrm{C}$. This indicates that the CuS/C-120 structure is more conducive for the transportation of internal electrons, increasing the conductivity of the material. As the experimental temperature increases, the degree of graphitization initially increases and subsequently decreases, indicating that the graphite crystal structure of $\mathrm{CuS} / \mathrm{C}-120$ is the best among the three samples.

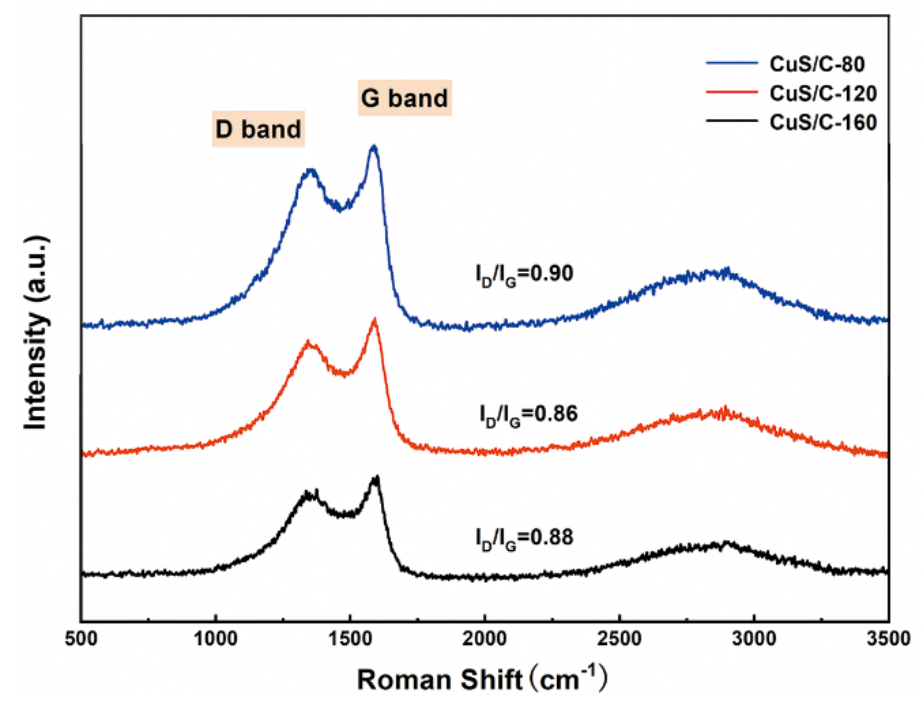

Figure 3. Raman spectra of CuS/C-80, CuS/C-120, and CuS/C-160 nanoparticles.

The morphologies and microstructures of the CuS/C-80, CuS/C-120, and CuS/C-160 samples were characterized using scanning electron microscopy (SEM, Figure $4 \mathrm{a}-\mathrm{f}$ ). When the experimental temperature reaches $80^{\circ} \mathrm{C}$, the granulation in the sample is manifest. When the temperature increases from 120 to $160{ }^{\circ} \mathrm{C}$, the nanoparticles are connected into a block. Further, when the temperature is $120^{\circ} \mathrm{C}$, they collide with other nanoparticles to form a dense cloud-like nanostructure. Compared with $\mathrm{CuS} / \mathrm{C}-160$ and $\mathrm{CuS} / \mathrm{C}-80, \mathrm{CuS} / \mathrm{C}-120$ exhibits a more regular flocculent network structure, with almost no agglomeration and a smoother surface. The homogeneous nanoparticles in the sample contain gaps between them. These gaps are beneficial for the diffusion and transfer of the electrolyte ions, which enhances the conductivity of the samples, endowing it with the best electrochemical properties among the samples. Therefore, temperature is the key factor that affects the structure of the materials. 

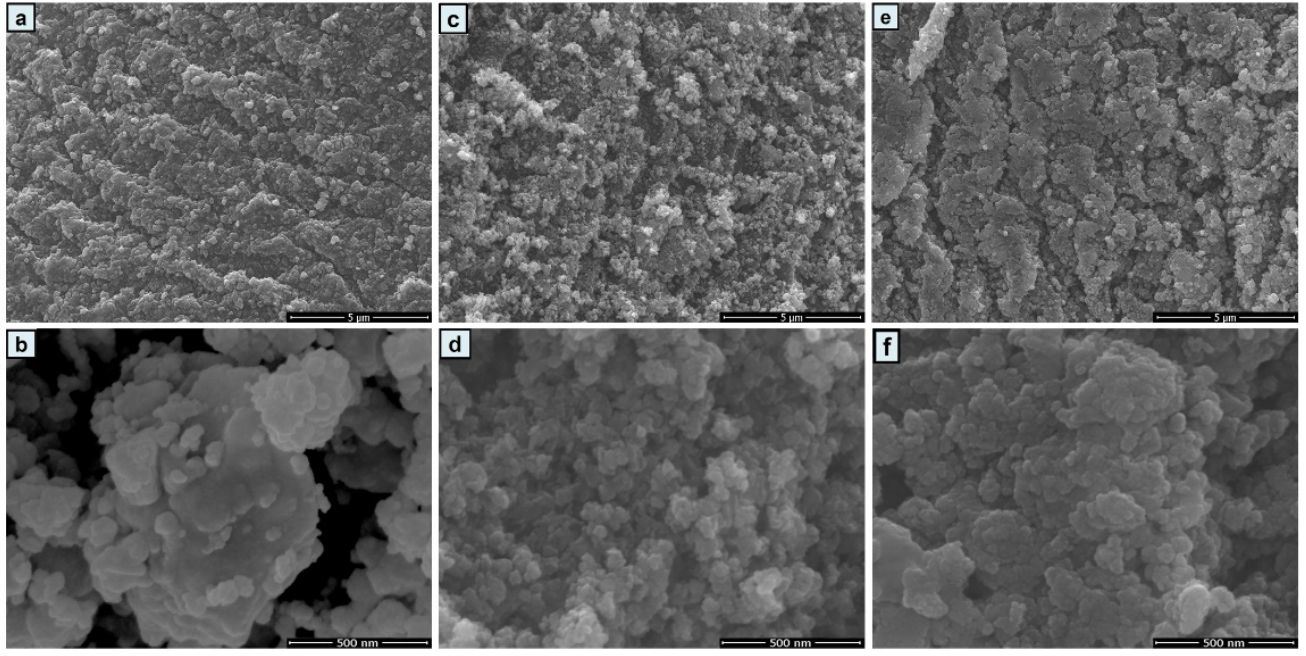

Figure 4. Low and high magnification SEM images of (a,b) CuS/C-80, (c,d) CuS/C-120, and (e,f) CuS/C-160.

The microstructure of the CuS/C-120 composite was examined using TEM. It can be seen from the images in Figure 5a,b that the CuS/C-120 nanometer-sized dense spatial cloud structure is clearly hierarchical. Further, the $\mathrm{CuS} / \mathrm{C}$ nanoparticles in the sample comprise elemental $\mathrm{Cu}, \mathrm{S}$, and $\mathrm{C}$, and $\mathrm{C}$ is embedded in the center of CuS/C. Polyhedral crystals of approximately $60 \mathrm{~nm}$ in size can be observed, and the $\mathrm{CuS} / \mathrm{C}$ nanoparticles are interconnected. The high-resolution transmission electron microscope image in Figure 5a shows lattice fringes with a distance of $0.281 \mathrm{~nm}$, which could be attributed to the (103) crystal plane. To confirm the coexistence of each element, the energy dispersive X-ray spectrometer coupled with the microscope was used to perform elemental mapping analysis, the results of which are shown in Figure 5c. SEM and TEM analysis showed that the internal structure of CuS/C is regulated by the experimental temperature. This nanostructure can be used to achieve convenient electron transport, which is helpful with respect to the electrochemical performances.

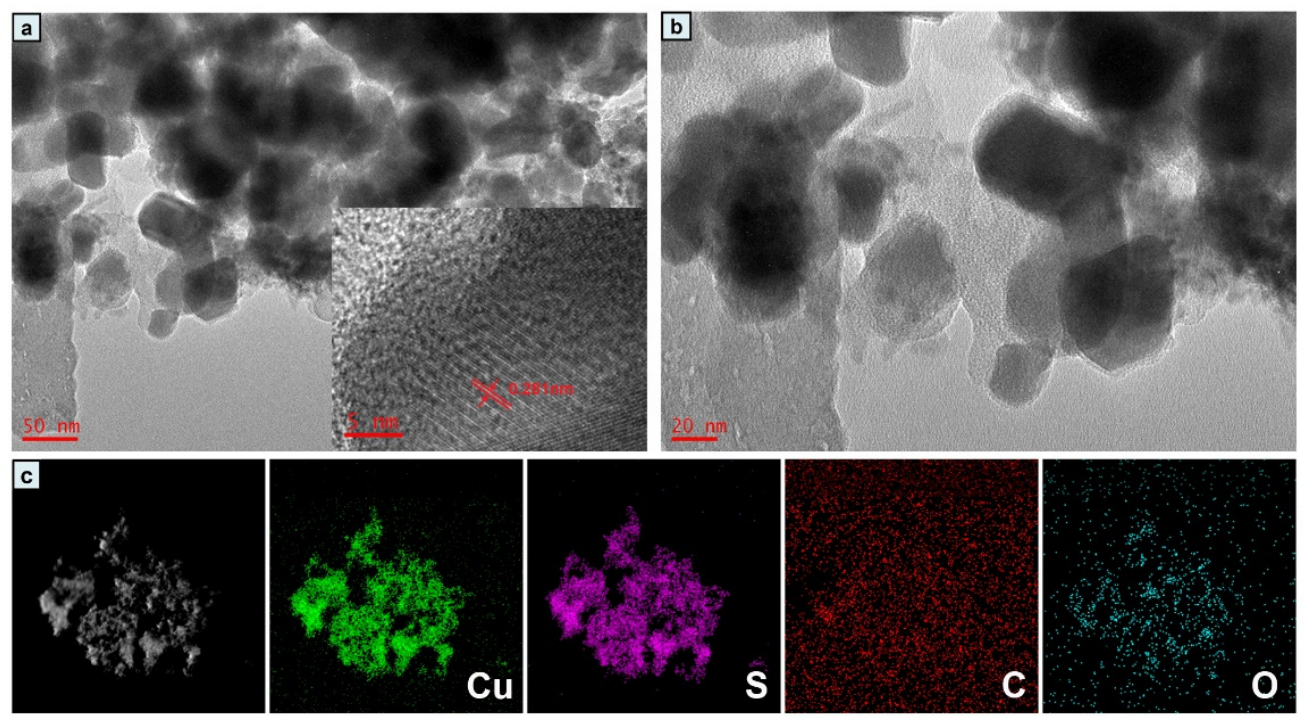

Figure 5. (a,b) TEM images of CuS-120 nanoparticles; (c) EDX mapping of Cu, S, C, O for CuS-120.

X-ray photoelectron spectroscopy (XPS) measurements were conducted to determine the elemental composition of CuS/C-120, and their results are presented in Figure 6. The spectrum exhibits signals containing $\mathrm{Cu}, \mathrm{S}, \mathrm{C}$, and $\mathrm{O}$ elements, and there is no other impurity element, as presented in Figure 6a. The $\mathrm{Cu} 2 \mathrm{p}$ spectrum is shown in Figure $6 \mathrm{~b}$. The main peaks located at $932.12 \mathrm{eV}$ and $951.86 \mathrm{eV}$ in the spectrum correspond to $\mathrm{Cu} 2 \mathrm{p}_{3 / 2}$ and $\mathrm{Cu} 2 \mathrm{p}_{1 / 2}$, respectively [31]. The peaks at $932.12 \mathrm{eV}$ and $951.68 \mathrm{eV}$ 
could be attributed to $\mathrm{Cu}^{2+}$ in $\mathrm{CuS}$ [32], whereas those at $933.55 \mathrm{eV}$ and $953.63 \mathrm{eV}$ can be fitted to $\mathrm{Cu}^{2+}$ in $\mathrm{CuSO}_{4}{ }^{2-}$ [33]. Figure 6c shows S 2p, where there are four main peaks at $162.17 \mathrm{eV}$ and $163.71 \mathrm{eV}$, which can be attributed to $S 2 p_{3 / 2}$ and $S 2 p_{1 / 2}$, respectively, and $162.11 \mathrm{eV}$ and $165.04 \mathrm{eV}$, which can be assigned to the elemental S in CuS [34]. In the same spectrum, the peaks at $161.3 \mathrm{eV}$ and $163.32 \mathrm{eV}$ can be assigned to the S-S dimers [35], and the peak at $168.65 \mathrm{eV}$ is characteristic of $\mathrm{SO}_{4}{ }^{2-}$ [36], which is present on the surface of $\mathrm{CuS} / \mathrm{C}-120$ because of the partial air oxidation of the sample surface. The XPS results denote that $\mathrm{CuS} / \mathrm{C}-120$ mainly comprises $\mathrm{Cu}^{2+}$ and $\mathrm{S}^{2-}$.
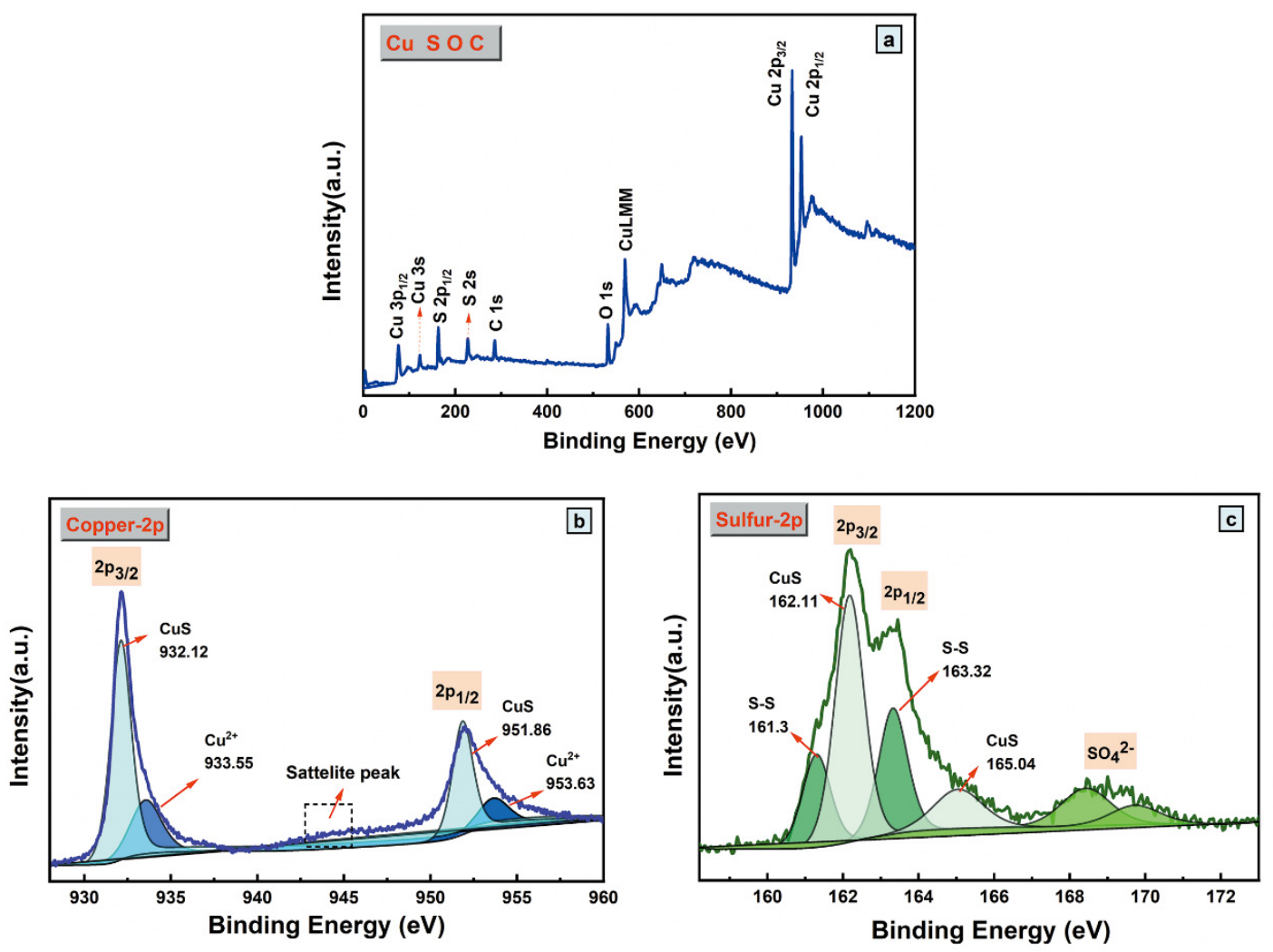

Figure 6. (a) Full XPS patterns of CuS/C-120; XPS patterns of (b) Cu 2p and (c) S 2p.

Fourier transform infrared (FTIR) spectroscopy is performed to investigate the compositions of the functional groups on the surface of the CuS/C-120 electrode material, and the results are presented in Figure 7. Five main absorption peaks can be observed in the spectra at 617.19, 1111.87, 1609.65, 2345.81, and $3432.65 \mathrm{~cm}^{-1}$. The absorption peaks between 617.19 and $1111.87 \mathrm{~cm}^{-1}$ are shown in more detail in the inset in Figure 7. The absorption peaks at 1111.87, 1609.65, and $2345.81 \mathrm{~cm}^{-1}$ can be attributed to the $\mathrm{C}-\mathrm{OH}, \mathrm{C}=\mathrm{O}$, and $\mathrm{C}=\mathrm{C}$ stretching vibrations, respectively. The absorption peak at $3432.65 \mathrm{~cm}^{-1} \mathrm{can}^{-}$ be attributed to the stretching of the $-\mathrm{OH}$ in the carboxyl group, providing the presence of bound $\mathrm{H}_{2} \mathrm{O}$ or ethanol molecules after the two-step hydrothermal reaction $[37,38]$. 


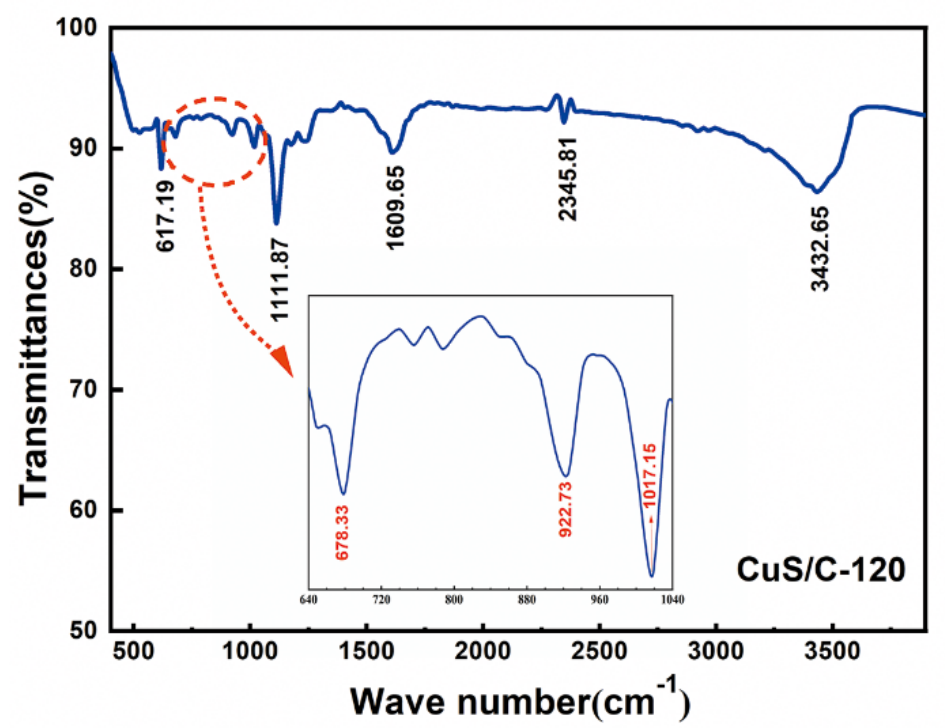

Figure 7. Fourier transform infrared spectroscopy (FTIR) spectra of the CuS/C-120 nanoparticles.

The specific surface area and pore size of a material are closely related to its electrochemical performance. Therefore, the specific surface area and pore size distribution of CuS/C-120 were measured and analyzed using the $\mathrm{N}_{2}$ adsorption-desorption isotherms at $77.350 \mathrm{~K}$, as shown in Figure $8 \mathrm{a}$, where the isotherms are type-IV with a $\mathrm{H}_{3}$ hysteresis loop. The hysteresis loop is obvious when the relative pressure is $\mathrm{p} / \mathrm{p}_{0}>0.3$. When $\mathrm{p} / \mathrm{p}_{0}>0.9$, the upward shift in $\mathrm{N}_{2}$ isotherm could be attributed to the existence of perforations in the sample. When $\mathrm{p} / \mathrm{p}_{0}<0.1$, there is no obvious upward shift in the isotherms, indicating that there are very few micropores in the sample. These results indicate that $\mathrm{CuS} / \mathrm{C}-120$ mostly exists as mesopores and macropores, forming a layered porous structure. In the initial stage of CuS formation, with the progress of the sulfidation reaction, the amount of $\mathrm{Cu}^{2+}$ required for $\mathrm{CuS}$ formation increased, and the volume of $\mathrm{CuS}$ nanoparticles gradually increased with the progress of sulfidation reaction. Pores were formed when ions passed through the CuS particles from the gap under the electric field force [39]. As the reaction continued, the pores gradually became larger and transformed into mesopores and macropores. Therefore, micropores, mesopores, and macropores were formed because of the different reaction times and temperatures. Besides, several mesoporous were formed during the carbonization [40]. Micropores can contribute to charge storage, macropores can serve as the "ion buffering reservoirs", and mesopores can facilitate to penetrate the electrolyte ions into the whole materials [41]. Figure $8 \mathrm{~b}$ shows the pore size distribution of CuS/C-120, which supports the existence of mesopores $(50 \mathrm{~nm})$ in its structure. A porous structure not only allows the rapid penetration of electrolytic ions into the electrode material but also provides several reactive sites for ion diffusion, reducing the ion diffusion distance. The average specific surface area of the prepared CuS/C-120 powder is $41.3709 \mathrm{~m}^{2} / \mathrm{g}$. The contact area between the electrode material and the electrolyte increases because of a high specific surface area, providing a good environment for the transport of ions and electrons, which is beneficial for redox reactions. Furthermore, a high specific surface area is one of the most important reasons for the excellent electrochemical performance of $\mathrm{CuS} / \mathrm{C}-120$. The $\mathrm{N}_{2}$ adsorption-desorption isotherm results were consistent with the previous PXRD, SEM/TEM, XPS, FTIR, and Raman spectroscopic analysis results. 

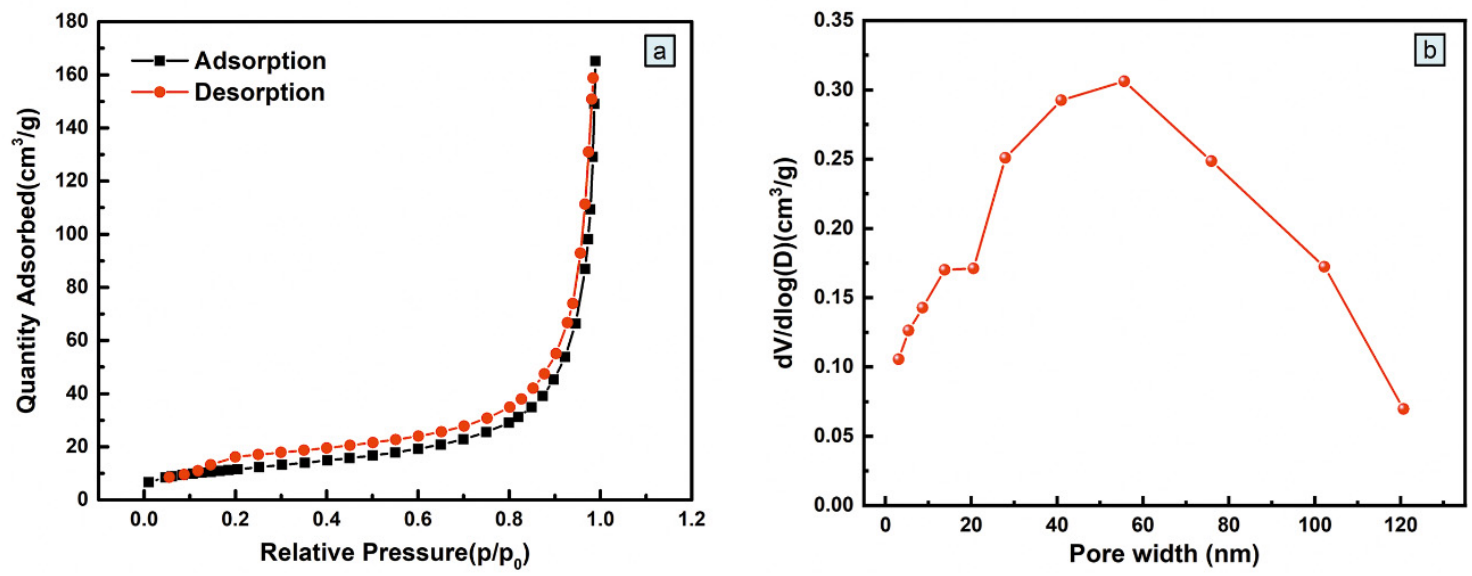

Figure 8. (a) $\mathrm{N}_{2}$ adsorption/desorption isotherms for the CuS/C-120 electrode material; (b) Pore size distribution of the CuS/C-120 electrode material.

\subsection{Electrochemical Performance}

Electrochemical test analysis was performed to further explore the effect of temperature on the electrochemical performance of the CuS/C electrode materials and improve the conductivity of the electrode materials at optimal temperatures. The $\mathrm{CV}$ curves of $\mathrm{CuS} / \mathrm{C}$ were recorded in the voltage window of $-0.3-0.6 \mathrm{~V}$ at a scan rate of $10 \mathrm{mV}^{-1}$ and different hydrothermal temperatures, as shown in Figure 9a. Among the $\mathrm{CV}$ curves of the three samples, that of $\mathrm{CuS} / \mathrm{C}-80$ exhibits a rectangular shape. The CV curves of CuS/C-120 and CuS/C-160 exhibit obvious redox peaks, indicating the occurrence of the redox reactions. Moreover, the loop area of CuS/C-120 is considerably larger than those of CuS/C- 80 and CuS/C-160. Therefore, it exhibits the highest specific capacitance. The specific capacitances of CuS/C-80, CuS/C-120, and CuS/C-160 are 110.76, 219.65, and $79.16 \mathrm{Fg}^{-1}$ at a scan rate of $10 \mathrm{mV}^{-1}$. Figure $9 \mathrm{~b}$ shows the charge-discharge curves (GCD) of the three samples at a current density of $0.5 \mathrm{Ag}^{-1}$. All three curves are approximately triangular in shape and are stable. Notably, CuS/C-120 has the longest discharge time (416.3 s), which is longer than those of CuS/C-80 (202.8 s) and CuS/C-160 (155.2 s). In addition, the calculated specific capacitances of $\mathrm{CuS} / \mathrm{C}$ electrodes based on the discharge curves are $112.67,231.32$, and $86.22 \mathrm{Fg}^{-1}$ at temperatures of $80^{\circ} \mathrm{C}, 120^{\circ} \mathrm{C}$, and $160^{\circ} \mathrm{C}$, respectively. These results are consistent with the $\mathrm{CV}$ curves. Figure $9 \mathrm{c}$, d show the histograms of the specific capacitances of the three samples at different current densities and scan rates. With an increase in the current density (scan rate), the specific capacitances of all the three samples decreased, because a high current density limits the rate of ion migration to the interior of the active material. Moreover, CuS/C-120 has the largest specific capacitance at different current densities owing to its internal structure, electrical conductivity, and large specific surface area. Figure 9e shows the alternating current (AC) impedance spectra of the three samples, which is an enlarged view of the high-frequency part of the spectrum. The Nyquist plots of the samples include semicircular and linear regions. Compared with CuS/C-80 and CuS/C-160, $\mathrm{CuS} / \mathrm{C}-120$ has the steepest Nyquist plot slope, exhibiting high specific capacitance. Thus, it exhibits superior electrochemical properties owing to its good rate performance, large pore volume, and high specific surface area. The results demonstrate that the capacitance of the composites is considerably dependent on the experimental temperature. 

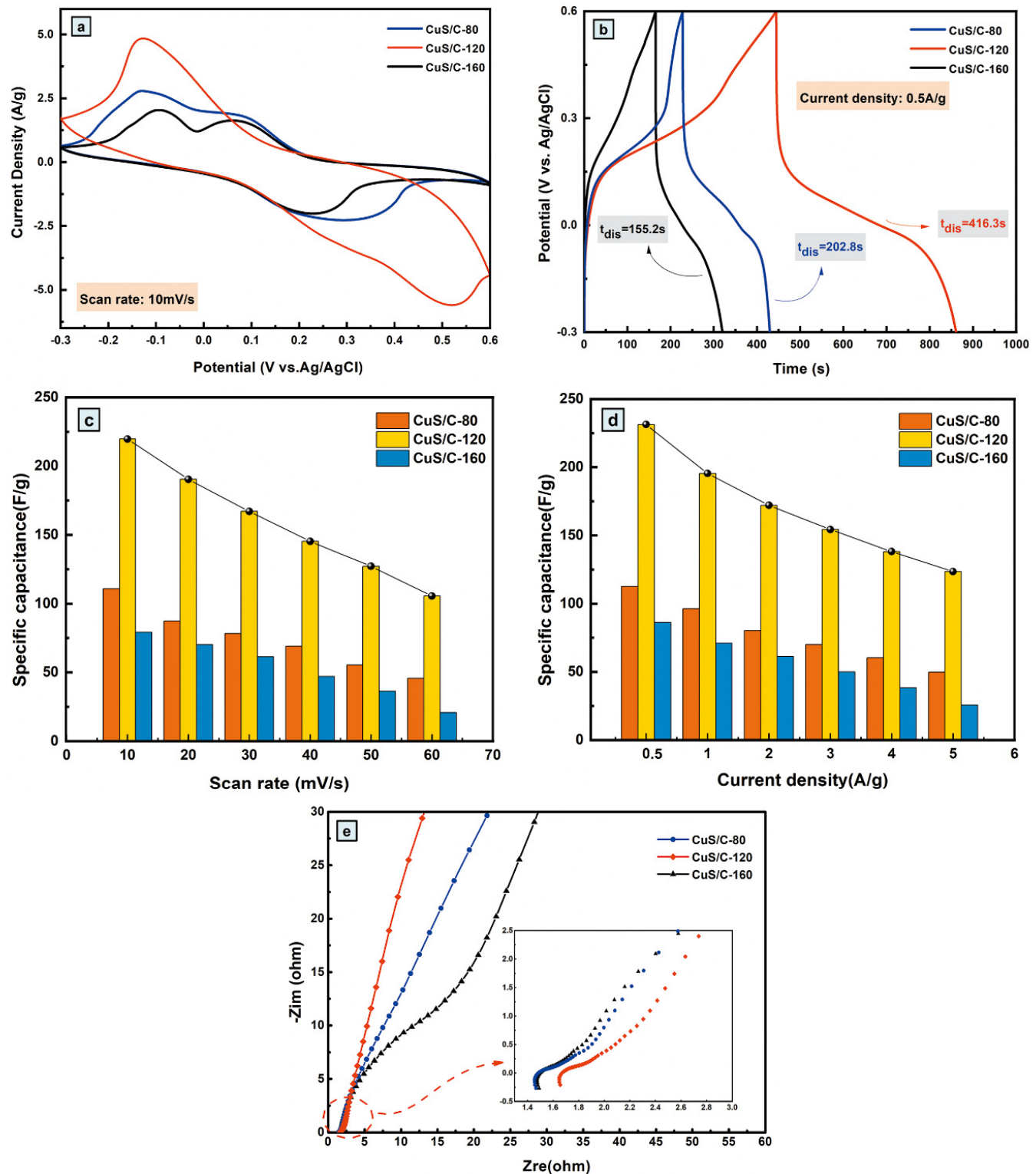

Figure 9. (a) Comparison cyclic voltammetry (CV) curves for CuS/C-80, CuS/C-120 and CuS/C-160 electrodes at $10 \mathrm{mV}^{-1}$; (b) Comparison charge-discharge curves for CuS/C-80, CuS/C-120, and CuS/C-160 electrodes at $0.5 \mathrm{Ag}^{-1}$; (c) The specific capacitance at different scan rates of CuS/C-80, CuS/C-120, and CuS/C-160 electrodes; (d) The specific capacitance at different current densities of CuS/C-80, CuS/C-120, and CuS/C-160 electrodes; (e) Nyquist electrochemical impedance spectra of CuS/C-80, $\mathrm{CuS} / \mathrm{C}-120$, and CuS/C-160 electrodes (inset: the enlarged high frequency part).

To improve its electrochemical performance, the conductive polymer polyaniline (PANI) was deposited on CuS/C-120 to obtain a highly conductive CuS/C-120@PANI nanocomposite electrode material. The CV curves of CuS/C-120@PANI at a scan rate of $5-70 \mathrm{mV}^{-1}$ are shown in Figure 10a. It can be observed from the $\mathrm{CV}$ scans that the current peak gradually increases with an increasing scan rate, maintaining a similar rectangular shape to that of the $C V$ curves of $C u S / C-120$, without obvious redox peaks, which indicates that CuS/C-120@PANI exhibited better reversibility when compared with that exhibited by $\mathrm{CuS} / \mathrm{C}-120$. The specific capacitance is proportional to the $\mathrm{CV}$ integral area; therefore, the CuS/C-120@PANI nanocomposite shows significantly enhanced capacitance, reflecting high charge storage efficiency because of the contribution of polyaniline. To evaluate the CuS/C-120@PANI nanocomposite, the rate performance was also analyzed by using the GCD curves obtained at various 
current densities. The GCD curves at various current densities are shown in Figure 10b, where the discharge time of the composite electrode gradually decreases from 0.5 to $5 \mathrm{Ag}^{-1}$. Based on Formula (2), the calculated specific capacitances of CuS/C-120@PANI are 460.66, 425.53, 371.16, 315.37, 268.99, and $237.00 \mathrm{Fg}^{-1}$ at discharge current densities of $0.5,1.0,2.0,3.0,4.0$, and $5.0 \mathrm{Ag}^{-1}$, respectively. However, the GCD curves are not deformed, and they remain approximately triangular, implying that the GCD curves are in good agreement with the CV results. The IR drop values obtained under different current densities are presented in Table 2.
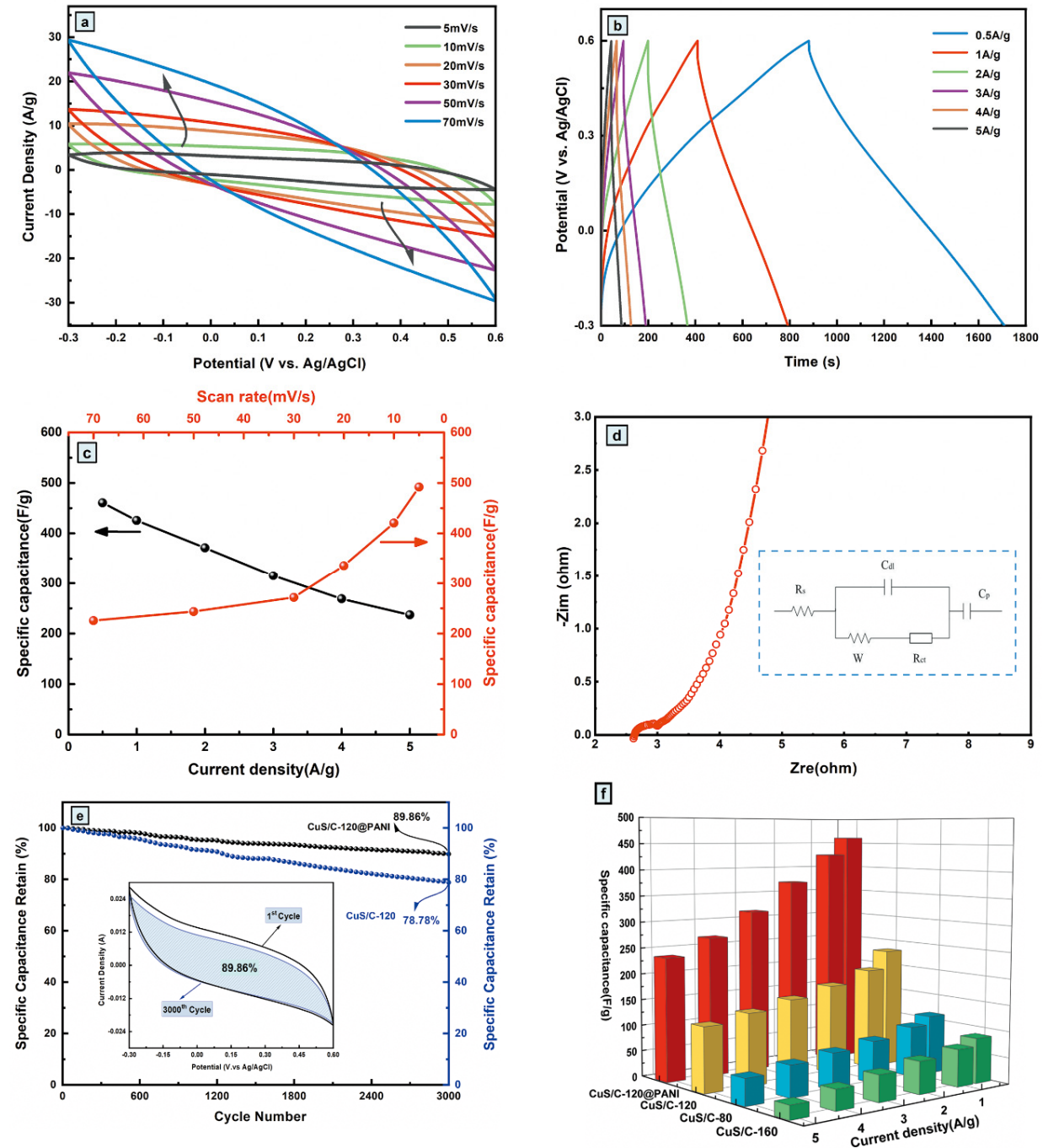

Figure 10. (a) CV curves at various scan rates for CuS/C-120@PANI electrode; (b) GCD curves at various current densities for CuS/C-120@PANI electrode; (c) Specific capacitance values of different various scan rates and current densities; (d) EIS curve of CuS/C-120@PANI with equivalent circuit inset; (e) Cycling performance of the CuS/C-120@PANI electrode at $10 \mathrm{mV}^{-1}$ for 3000 cycles; (f) Specific capacitance of CuS/C-80, CuS/C-120, CuS/C-160 and CuS/C-120@PANI at different current densities.

Table 2. The value of IR drops at different current densities for CuS/C-120@PANI electrode. PANI: polyaniline.

\begin{tabular}{ccccccc}
\hline Current Density $\left(\mathbf{A g}^{-\mathbf{1}}\right)$ & 0.5 & 1 & 2 & 3 & 4 & 5 \\
\hline IR Drop (V) & 0.03 & 0.05 & 0.11 & 0.15 & 0.20 & 0.26 \\
\hline
\end{tabular}

The voltage loss is minimum when the current density is the lowest. The specific capacitance of CuS/C-120@PANI obtained under different current densities and scan rates are presented in 
Figure 10c, exhibiting a good rate capability. The AC impedance spectrum of the composite electrode is presented in Figure 10d. The inset shows the fitting circuit $R(C(W R)) C$, where $R_{s}, R_{c t}, C_{d l}, W$, and $C_{p}$ represent the solution impedance, charge transfer impedance, electric double-layer capacitance, Warburg impedance, and faradaic pseudo capacitance, respectively. In the high-frequency region, the $R_{\mathrm{ct}}$ value is large, indicating that the porous structure of the composite electrode is conducive to charge transfer. Furthermore, in the low-frequency region, the slope is approximately vertical, indicating that the electrode exhibits an electrochemical behavior approximately similar to pure capacitance. The EIS results confirm the excellent supercapacitive behavior of CuS/C-120@PANI electrode. Figure 10e shows the cyclic stability of the CuS/C-120@PANI after 3000 cycles at a scan rate of $10 \mathrm{mV}^{-1}$. The capacitance retention rate of the electrode became $89.86 \%$, implying good cyclic stability. Figure $10 \mathrm{f}$ shows a three-dimensional comparison of the capacitance retention of CuS/C-80, CuS/C-120, CuS/C-160, and CuS/C-120@PANI under different current densities. The CuS/C-120@PANI composite possesses the largest capacitance among them all. The capacitance characteristics are optimal when the hydrothermal temperature is $120^{\circ} \mathrm{C}$ at different experimental temperatures. Therefore, the experimental temperature was considered to be the key factor that affects the performance of the electrode material. Further, the combination of PANI with CuS/C-120 enhances its performance. The positive synergistic effects between PANI and CuS/C-120 can enhance the corresponding electrochemical characteristics. CuS/C-120@PANI was the most suitable electrode material for use in SCs and could play an important role in the field of materials.

\section{Conclusions}

In summary, CuS/C electrode materials with an excellent structure were successfully prepared using a two-step hydrothermal method. The curing temperature exhibited an important effect on the structural properties and electrochemical performance of the materials. In a three-electrode test system, the CuS/C-120 electrode exhibited a specific capacitance of $231.32 \mathrm{Fg}^{-1}$ at $0.5 \mathrm{Ag}^{-1}$, which is considerably higher than the values observed for CuS/C-80 and CuS/C-160. To further improve the capacitance performance of CuS/C-120 in terms of conductivity, a CuS/C-120@PANI electrode nanocomposite was prepared by depositing the conductive polymer PANI on the CuS/C-120 electrode, resulting in a specific capacitance of $425.53 \mathrm{Fg}^{-1}$ at $1 \mathrm{Ag}^{-1}$ in $3 \mathrm{M} \mathrm{KCL}$. In addition, the composite electrode retained $89.86 \%$ of its capacitance after 3000 cycles. CuS/C-120 exhibited excellent electrochemical performance, which could be attributed to its high specific surface area, good microstructure, and excellent pore size distribution when compared with those of CuS/C-80 and CuS/C-160. Therefore, the experimental temperature was the key factor that affected the performance of the initial electrode material prior to the formation of the composite, implying that when combined with PANI, CuS/C-120@PANI is an extremely promising material that will hopefully be widely used in high-performance battery materials.

Author Contributions: S.Z. and Q.L. designed the project and the experiments. S.Z. and Y.X. performed the experiments. S.Z. wrote the paper with support from Q.L. All authors contributed to the general discussion. All authors have read and agree to the published version of the manuscript.

Funding: This work was financially supported by the Fundamental Research Funds for the Central Universities of China (NO. 2018ZD001) and Natural Science Foundation Project of China (NO. 51607070).

Acknowledgments: The authors are thankful to the State Key Laboratory of New Energy and Electric Power Systems. This work was supported by the Fundamental Research Funds for the Central Universities of China (NO. 2018ZD001) and Natural Science Foundation Project of China (NO. 51607070).

Conflicts of Interest: The authors declare no conflict of interest.

\section{References}

1. Wang, Y.; Xia, Y. Recent progress in supercapacitors: From materials design to system construction. Adv. Mater. 2013, 25, 5336-5342. [CrossRef] [PubMed]

2. El-Kady, M.F.; Strong, V.; Dubin, S.; Dubiin, S.; Kaner, B.R. Laser scribing of high performance and flexible graphene-based electrochemical capacitors. Science 2011, 335, 1326-1330. [CrossRef] 
3. Song, W.; Li, X.; Fan, L. Biomass derivative/graphene aerogels for binder-free supercapacitors. Energy Storage Mater. 2016, 3, 113-122. [CrossRef]

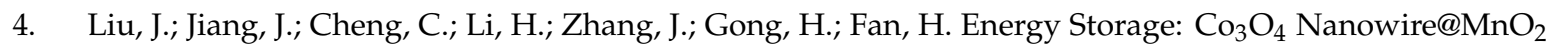
Ultrathin Nanosheet Core/Shell Arrays: A New Class of High-Performance Pseudocapacitive Materials. Adv. Mater. 2011, 23, 2076-2081. [CrossRef]

5. Zhu, Y.; Wang, Y.; Shi, Y.; Wong, J.; Yang, H. CoO nanoflowers woven by CNT network for high energy density flexible micro-supercapacitor. Nano Energy 2014, 3, 46-54. [CrossRef]

6. Song, W.; Song, K.; Fan, L. A Versatile Strategy toward Binary Three-Dimensional Architectures Based on Engineering Graphene Aerogels with Porous Carbon Fabrics for Supercapacitors. ACS Appl. Mater. Inter. 2015, 7, 4257-4264. [CrossRef]

7. Yang, B.; She, Y.; Zhang, C.; Kang, S.; Zhou, J.; Hu, W. Nitrogen Doped Intercalation $\mathrm{TiO}_{2} / \mathrm{TiN} / \mathrm{Ti}_{3} \mathrm{C}_{2} \mathrm{~T}_{\mathrm{x}}$ Nanocomposite Electrodes with Enhanced Pseudocapacitance. Nanomaterials 2020, 10, 345. [CrossRef]

8. Zhao, Y.; Liu, J.; Horn, M.; Motta, N.; Hu, M.; Li, Y. Recent advancements in metal organic framework based electrodes for supercapacitors. Sci. China Mater. 2018, 61, 159-184. [CrossRef]

9. Tan, P.; Wu, Z.; Chen, B.; Xu, H.; Cai, W.; Ni, M. Exploring oxygen electrocatalytic activity and pseudocapacitive behavior of $\mathrm{Co}_{3} \mathrm{O}_{4}$ nanoplates in alkaline solutions. Electrochim. Acta 2019, 310, 86-95. [CrossRef]

10. Ju, H.; Song, W.; Fan, L. Rational design of graphene/porous carbon aerogels for high-performance flexible all-solid-state supercapacitors. J. Mater. Chem. A 2014, 2, 10895-10903. [CrossRef]

11. Dai, K.; Lv, L.; Lu, H.; Liang, C.; Geng, L.; Zhu, G. Large-scale synthesis of cobalt sulfide/carbon nanotube hybrid and its excellent electrochemical capacitance performance. Mater. Lett. 2016, 176, 42-45. [CrossRef]

12. Yang, Y.; Fei, H.; Ruan, G.; Xiang, C.; Tour, J. Edge-oriented $\mathrm{MoS}_{2}$ nanoporouse films as flexible electrodes for hydrogen evolution reactions and supercapacitor devices. Adv. Mater. 2014, 26, 8163-8168. [CrossRef] [PubMed]

13. Li, X.; Zhou, K.; Zhou, J.; Shen, J.; Ye, M. CuS nanoplatelets arrays grown on graphene nanosheets as advanced electrode materials for supercapacitor applications. J. Mater. Sci. Technol. 2018, 34, 2342-2349. [CrossRef]

14. Liang, H.; Shuang, W.; Zhang, Y.; Chao, S.; Han, H.; Wang, X.; Zhang, H.; Yang, L. Graphene-like Multilayered CuS Nanosheets Assembled into Flower-like Microspheres and Their Electrocatalytic Oxygen Evolution Properties. ChemElectroChem 2018, 3, 494-500. [CrossRef]

15. Huang, K.; Zhang, J.; Xing, K. One-step synthesis of layered CuS/multi-walled carbon nanotube nanocomposites for supercapacitor electrode material with ultrahigh specific capacitance. Electrochim. Acta 2014, 149, 28-33. [CrossRef]

16. Xue, G.; Huang, N.; Zhao, N.; Xiao, F.; Wei, W. Hollow $\mathrm{Al}_{2} \mathrm{O}_{3}$ spheres prepared by a simple and tunable hydrothermal method. RSC Adv. 2015, 5, 13385-13391. [CrossRef]

17. Yang, J.; Xiong, P.; Zheng, C.; Qiu, H.; Wei, M. Metal-organic frameworks: A new promising class of materials for a high-performance supercapacitor electrode. J. Mater. Chem. A 2014, 2, 16640-16644. [CrossRef]

18. Zhu, Z.; Wang, Z.; Yan, Z.; Zhou, R.; Wang, Z.; Chen, C. Facile synthesis of MOF-derived porous spinel zinc manganese oxide/carbon nanorods hybrid materials for supercapacitor application. Ceram. Int. 2018, 44, 20163-20169. [CrossRef]

19. Gambou-Bosca, A.; Bélanger, D. Effect of the formulation of the electrode on the pore texture and electrochemical performance of the manganese dioxide-based electrode for application in a hybrid electrochemical capacitor. J. Mater. Chem. A 2014, 2, 6463-6473. [CrossRef]

20. Masarapu, C.; Zeng, H.; Hung, K.; Wei, B. Effect of temperature on the capacitance of carbon nanotube supercapacitors. ACS Nano 2009, 3, 2199-2206. [CrossRef]

21. Ren, L.; Zhang, Z.; Kang, L.; Xu, H.; Shi, F.; Lei, Z.; Liu, Z. Three-dimensional tubular $\mathrm{MoS}_{2} /$ PANI hybrid electrode for high rate performance supercapacitor. ACS Appl. Mater. Inter. 2015, 7, 28294-28302. [CrossRef] [PubMed]

22. Wang, T.; Zhang, S.; Wang, H. Binary NiCu layered double hydroxide nanosheets for enhanced energy storage performance as supercapacitor electrode. Sci. China Mater. 2018, 61, 296-302. [CrossRef]

23. Nguyen, D.; Yoon, H. Recent advances in nanostructured conducting polymers: From synthesis to practical applications. Polymers 2016, 8, 118. [CrossRef] [PubMed] 
24. Zhu, C.; He, Y.; Liu, Y.; Kazantseva, N.; Saha, P.; Cheng, Q. ZnO@MOF@PANI core-shell nanoarrays on carbon cloth for high-performance supercapacitor electrodes. J. Energy Chem. 2019, 25, 123-131. [CrossRef]

25. Jafari, E.; Moradi, M.; Borhani, S.; Bigdeli, H.; Hajati, S. Fabrication of hybrid supercapacitor based on rod-like HKUST-1@polyaniline as cathode and reduced graphene oxide as anode. Phys. E 2018, 99, 16-23. [CrossRef]

26. Wang, L.; Feng, X.; Ren, L.; Piao, Q.; Zhong, J.; Wang, Y.; LI, H.; Chen, Y.; Wang, B.L.; Wang, X.; et al. Flexible Solid-State Supercapacitor Based on a Metal-Organic Framework Interwoven by Electrochemically-Deposited PANI. J. Am. Chem. Soc. 2015, 137, 4920-4923. [CrossRef]

27. Sevillano, G.; Luna, J.; Dubbeldam, D.; Calero, S. Molecular Mechanisms for Adsorption in Cu-BTC Metal Organic Framework. J. Phys. Chem. C 1999, 117, 11357-11366. [CrossRef]

28. Hao, X.; Pritzker, M. Pulsed electrodeposition of nickel hexacyanoferrate films for electrochemically switched ion exchange. Sep. Purif. Technol. 2018, 63, 407-414. [CrossRef]

29. Theerthagiri, J.; Thiagarajan, K.; Senthilkumar, B.; Khan, Z.; Senthil, R.A.; Arunachalam, P.; Madhavan, J.; Ashokkumar, M. Synthesis of Hierarchical Cobalt Phosphate Nanoflakes and their Enhanced Electrochemical Performances for Supercapacitor Applications. ChemistrySelect 2017, 2, 201-210. [CrossRef]

30. Yasin, A.; Jeong, J.; Mohamed, I.; Park, C.; Kim, C. Fabrication of N-doped\&SnO 2 -incorporated activated carbon to enhance desalination and bio-decontamination performance for capacitive deionization. J. Alloy. Comp. 2017, 729, 764-775.

31. Ji, D.; Zhou, Y.; Tong, J.; Wang, J.; Zhu, M.; Chen, T.; Yuan, A. Facile fabrication of MOF-derived octahedral $\mathrm{CuO}$ wrapped 3D graphene network as binder-free anode for high performance lithium-ion batteries. Chem. Eng. J. 2017, 313, 1623-1632. [CrossRef]

32. Cras, F.; Pecquenard, B.; Martinez, H.; Martin, L. Comprehensive X-ray Photoelectron Spectroscopy Study of the Conversion Reaction Mechanism of $\mathrm{CuO}$ in Lithiated Thin Film Electrodes. J. Phys. Chem. C 2013, 117, $4421-4430$.

33. Ung, T.; Nguyen, Q.; Christopher, M.; Georgi, M.; Karen, W. Synthesis of CuS and CuS/ZnS core/shell nanocrystals for photocatalytic degradation of dyes under visible light. Catal. Commun. 2014, 44, 62-67.

34. Yi, X.; Riedinger, A.; Prato, M.; Casu, A.; Genovese, A.; Guardia, P.; Sottini, S.; Sangregorio, C.; Miszta, K.; Ghosh, S.; et al. Copper Sulfide Nanocrystals with Tunable Composition by Reduction of Covellite Nanocrystals with Cu $\backslash \mathrm{r}^{+} \backslash \mathrm{r}$ Ions. J. Am. Chem. Soc. 2013, 135, 17630-17637.

35. Li, L.; Li, R.; Gai, S.; Ding, S.; He, F.; Zhang, M.; Yang, P. $\mathrm{MnO}_{2}$ Nanosheets Grown on Nitrogen-Doped Hollow Carbon Shells as a High-Performance Electrode for Asymmetric Supercapacitors. Carbon 2015, 21, 7119-7126.

36. Kar, P.; Farsinezhad, S.; Zhang, X.; Shankar, K. Anodic $\mathrm{Cu}_{2} \mathrm{~S}$ and $\mathrm{CuS}$ nanorod and nanowall arrays: Preparation, properties and application in $\mathrm{CO}_{2}$ photoreduction. Nanoscale 2014, 6, 14305-14318. [CrossRef]

37. Yu, B.; Fang, J.; Huang, E. Characteristics of the Raman spectra of archaeological malachites. J. Raman. Spectrosc. 2013, 44, 630-636. [CrossRef]

38. Kumar, R.; Kumar, S.; Kulandainathan, M. Efficient electrosynthesis of highly active $\mathrm{Cu}_{3}(\mathrm{BTC})_{2}$-MOF and its catalytic application to chemical reduction. Micropor. Mesopor. Mater. 2013, 168, 57-64. [CrossRef]

39. Li, L.; Duan, W.; Yuan, Q. Hierarchical $\gamma-\mathrm{Al}_{2} \mathrm{O}_{3}$ monoliths with highly ordered $2 \mathrm{D}$ hexagonal mesopores in microporous walls. Chem. Commun. 2009, 41, 6174-6176. [CrossRef]

40. Chen, L.; Ji, T.; Mu, L.; Zhu, J. Cotton fabric derived hierarchically porous carbon and nitrogen doping for sustainable capacitor electrode. Carbon 2017, 111, 839-848. [CrossRef]

41. Feng, D.; Lv, Y.; Wu, Z.; Dou, Y.; Han, L.; Sun, Z.; Xia, Y.; Zheng, G.; Zhao, D. Freestanding mesoporous carbon thin films with highly ordered pore architectures for nanodevices. J. Am. Chem. Soc. 2011, 133, 15148-15156. [CrossRef] [PubMed]

(C) 2020 by the authors. Licensee MDPI, Basel, Switzerland. This article is an open access article distributed under the terms and conditions of the Creative Commons Attribution (CC BY) license (http://creativecommons.org/licenses/by/4.0/). 